The analysis of operating conditions of induction traction motors as part of traction electric drives of electric locomotives reported here has revealed that they are pozered by autonomous voltage inverters with asymmetric non-sinusoidal voltage. It was established that the induction motor operation may be accompanied by defects caused by the asymmetrical modes of the motor stator. A model of the induction motor has been proposed that takes into consideration changes in the values of mutual inductance of phases and complete inductance of the magnetization circuit due to changes in the geometric dimensions of the winding caused by a certain defect. An algorithm that considers the saturation of the magnetic circuit of the electric motor has been proposed.

This approach to modeling an induction motor is important because if one of the stator's windings is damaged, its geometry changes. This leads to a change in the mutual inductance of phases and the complete inductance of the magnetization circuit. Existing approaches to modeling an induction motor do not make it possible to fully take into consideration these changes.

The result of modeling is the determined starting characteristics for an intact and damaged engine. The comparison of modeling results for an intact engine with specifications has shown that the error in determining the controlled parameters did not exceed $5 \%$. The modeling results for the damaged engine demonstrated that the nature of change in the controlled parameters did not contradict the results reported by other authors. The discrepancy in determining the degree of change in the controlled parameters did not exceed $10 \%$. That indicates a high reliability of the modeling results.

The proposed model of an induction electric motor could be used to investigate electromagnetic processes occurring in an electric motor during its operation as part of the traction drive of electric locomotives

Keywords: induction traction motor, traction drive of electric locomotive, asymmetry of windings, saturation of the magnetic circuit
UDC 629.429.3:621.313

DOI: $10.15587 / 1729-4061.2021 .236825$

\title{
IMPROVING A MODEL OF THE INDUCTION TRACTION MOTOR OPERATION INVOLVING NON- SYMMETRIC STATOR WINDINGS
}

\author{
Sergey Goolak \\ $\mathrm{PhD}$, Senior Lecturer* \\ Borys Liubarskyi \\ Corresponding author \\ Doctor of Technical Sciences, Professor $* * *$ \\ E-mail: Iboris1911@ukr.net \\ Svitlana Sapronova \\ Doctor of Technical Sciences, Professor \\ Department of Cars and Carriage Facilities** \\ Viktor Tkachenko
}

Doctor of Technical Sciences, Professor, Head of Department*

levgen Riabov

$\mathrm{PhD}$, Associate Professor***

Marina Glebova

$\mathrm{PhD}$, Associate Professor

Department of Alternative Electric Power Engineering and Electrical Engineering

O. M. Beketov National University of Urban Economy in Kharkiv

Marshala Bazhanova str., 17, Kharkiv, Ukraine, 61002

*Department of Electromechanics and Rolling Stock of Railways**

** State University of Infrastructure and Technologies

Kyrylivska str., 9, Kyiv, Ukraine, 04071

***Department of Electrical Transport and Diesel Locomotive National Technical University «Kharkiv Polytechnic Institute» Kyrpychova str., 2, Kharkiv, Ukraine, 61002

Received date 08.05.2021 Accepted date 23.06.2021 Published date 31.08.2021
How to Cite: Goolak, S., Liubarskyi, B., Sapronova, S., Tkachenko, V., Riabov, I., Glebova, M. (2021). Improving a model of the induction traction motor operation involving non-symmetric stator windings. Eastern-European Journal of Enterprise Technologies, 4 (8 (112)), 45-58. doi: https://doi.org/10.15587/1729-4061.2021.236825

\section{Introduction}

It is impossible to manage railroad electric rolling stock efficiently without optimal control over all its components $[1,2]$. The rolling stock operation is associated with high electrical consumption, which renders relevance to the task of reducing losses within its systems, primarily in the traction electric drive [3, 4].

In order to find ways to reduce losses in the traction electric drive, electrodynamic processes in its components should be investigated. Studying electrodynamic processes in the traction electric drive of the electric rolling stock requires that its simulation model should be built, which would make it possible to determine certain parameters of it with high accuracy [5].
The modern rolling stock commonly exploits induction traction electric motors (ITM) as traction electric motors. This is because induction traction electric motors have several advantages compared to collector traction electric motors such as greater power at the same masssized parameters, the simplicity of design, and greater efficiency [6].

There are several approaches to modeling induction electric motors. They are primarily associated with the choice of a coordinate system. The simplest approach is to build a mathematical model of an induction motor in single-phase coordinates $[7,8]$. A model of the induction motor in single-phase coordinates is effective under the condition of symmetry of all engine windings. Otherwise, the use of single-phase coordinates is invalid. 
Asymmetric modes [9] may occur during the induction motor operation in the stator windings, for one reason or another. A three-phase coordinate system $[10,11]$ is used for modeling such modes of operation of the induction motor.

In three-phase induction electric motors, the stator and rotor magnetic circuits are permeated with a rotating magnetic flux with a corresponding pole $[12,13]$. Saturation from the main magnetic flux is created by all phases throughout the entire magnetic system. Given this, when building a model of the induction motor, one should take into consideration the effect of saturation on the value of the main inductance of the three-phase induction motor.

When modeling induction electric motors, the right choice of active resistance in the magnetizing circle is essential, which takes into consideration losses in the magnetic circuit of the electric motor [14]. Losses in the magnetic circuit affect determining such energy indicators of the induction motor as a power factor and efficiency.

Constructing a mathematical model of the induction traction electric motor providing for the possibility of examining the asymmetric modes of the stator, taking into consideration the saturation of the magnetic circle and losses in the magnetic circuit, would make it possible to achieve high accuracy in the calculations of electrodynamic processes in the electric motor. Such a model could enable determining with high accuracy the energy indicators of both the traction electric motor and the traction drive of the electric locomotive. This testifies to the relevance of the topic of this study involving the modeling of the induction traction motor operation.

\section{Literature review and problem statement}

The choice of procedure for constructing a mathematical model of the induction traction motor is associated with the possibility of taking into consideration a series of assumptions $[15,16]$. First of all, it concerns the power supply system of the induction traction motor. Several authors recommend that the power supply system of the induction motor should be considered symmetrical and sinusoidal while the stator and rotor windings - symmetrical. One should also assume that the stator and rotor of the induction machine are smooth.

When arranging a traction drive with induction motors, there are several methods for adjusting the motor shaft rotation frequency. These are current control [17], vector control [18], and direct torque control [19]. In all the specified methods for arranging a traction drive with induction motors, electric motors are powered by an autonomous voltage inverter. The choice of optimal modes of operation depending on the modes of movement of a vehicle was tackled in work [20], which considered the basic modes of operation of the traction induction drive. Since it is impossible, when implementing an autonomous voltage inverter, to select its elements with completely identical parameters, the voltage system at the inverter output would be asymmetrical [21]. Work [22] considers the modes of operation of the induction traction drive in a rolling stock with energy storage. However, the choice of engine parameters is carried out on the basis of a mathematical model with a large number of assumptions. In addition, underlying the algorithm for managing the valves of the autonomous voltage inverter is pulse-wide modulation (PWM). When using an autonomous inverter with PWM to power the traction induction motor, a dilemma arises. It is associated with the following factors. On the one hand, the higher the sampling rate for the control signal when arranging PWM, the closer the phase current shape to the sinusoid. That indicates a significant main harmonica of the phase voltage. On the other hand, force transistors used as power keys in an autonomous voltage inverter are low-frequency devices. Even within the operating range of frequencies, increasing the sampling rate leads to an increase in the heating of transistors. That, in turn, leads to an increase in the active resistance of transistors and, as a result, to a decrease in the efficiency of the inverter. In other words, it is almost impossible to ensure such a voltage at the output of the autonomous inverter that, when powering the traction induction electric motor, could make its phase currents almost sinusoidal [23]. That is, when modeling a traction induction motor, it is incorrect to assume that the voltage supply system for an induction motor is symmetrical and sinusoidal.

A solution to this problem is suggested in studies [24, 25]. Their author used a three-phase coordinate system for modeling and proposed to implement the electric part of the electric motor in the form of elements of an electrical circuit - inductances and resistances. That has allowed him to simulate the operation of an induction electric motor powered by an asymmetrical non-sinusoidal voltage system. In addition, the author of those studies offered algorithms for choosing the active resistance of the magnetizing circuit and taking into consideration the saturation of the magnetic circuit of the induction electric motor. Despite the proper approach to modeling electromechanical processes in an induction motor, the cited studies do not propose the implementation of asymmetric modes that may occur in the traction induction electric motor during its operation. In the event of such modes, not only the active resistances and inductances of the damaged phases change but also the mutual inductance of phases and the complete (main) inductance of the magnetization circuit. A procedure for determining the mutual inductiveness of the induction electric motor when changing the geometrical parameters of its windings is reported in [26]. However, the cited study gives only the algorithm in the form of a mathematical apparatus and does not show the implementation of the algorithm.

The implementation of the algorithm proposed in work [26] is illustrated in [16]. However, the cited work took into consideration only the changes in the local mutual inductances of stators and rotors when changing the geometric dimensions of windings. Local mutual inductances induced by magnetic links between the stator and rotor windings were not taken into consideration in [16]. A model of the induction motor given in [16] is executed in the form of structural schemes; it cannot account for those local mutual inductances that are the functions of the motor shaft rotation angle.

The issue related to accounting for the local mutual inductances induced by magnetic links between the stator and rotor windings can be solved by choosing the model proposed in study [25] as the basic model of the induction motor. In the cited study, the mutual inductances of phases in the electrical part of the model are replaced by controlled voltage sources.

That could make it possible to implement an algorithm for changing the mutual inductances of phases when changing the geometric dimensions of windings. 
However, it is still an open question to take into consideration the saturation of the magnetic circuit of the electric motor when changing the geometric dimensions of its windings. Study [25] proposed an algorithm that considers the saturation, but for symmetrical windings. In works [27, 28], it was noted that under the asymmetric modes of induction motor operation, saturation from the main magnetic flux is created by all phases throughout the entire magnetic system unevenly. Therefore, when setting an asymmetric mode, the effect of saturation on the mutual inductance of each phase should be taken into consideration separately and, in addition, the effect of saturation on the value of the main inductance of the three-phase induction electric motor must be accounted for.

Our review allows us to assert that modeling an induction traction electric motor taking into consideration the possible asymmetric modes of its windings and accounting for the saturation of the magnetic circuit is expedient.

\section{The aim and objectives of the study}

The purpose of this study is to improve a mathematical model for simulating the traction induction electric motor providing for the possibility of managing the asymmetric mode of stator windings. This could make it possible to properly take into consideration the impact of defects on the operation of traction induction electric motors in order to study electromagnetic processes occurring during their operation.

To accomplish the aim, the following tasks have been set:

- to finalize the basic model of the induction motor in three-phase coordinates, whose electric part employs electrical elements, all others are executed in the form of structural schemes in order to implement an asymmetric mode;

- to model an induction motor taking into consideration the losses in steel and the saturation of the magnetic circuit;

- to develop an algorithm that would account for a change in the mutual inductances of phases and the main inductance when changing the geometric dimensions of windings due to changing the integrated resistance of one or more windings and to implement the algorithm in the MATLAB programming environment;

- to simulate, using the programming environment MATLAB, an induction motor with asymmetric stator windings and compare the nature of changes in the controlled parameters with similar parameters acquired from the model of an intact motor;

- to check the model for adequacy.

\section{The study materials and methods}

We studied the traction induction motor operation based on its mathematical model whose equations are recorded in three-phase coordinates. These equations were supplemented with equations that make it possible to take into consideration a change in the values of mutual inductances of phases and the main inductance of the magnetization circle when changing the geometry of the stator winding.

The simulation model of the traction induction motor is implemented in the MATLAB programming environment.
Studying the electric motor operation using the simulation model involved two experiments. The first experiment was to obtain starting characteristics for an intact engine. The other - on condition that in phase A of the stator's winding there was an inter-turn short circuit of $10 \%$ of the winding.

For the first case, we validated the proposed solutions by comparing the engine parameters acquired from the model with the specifications of the prototype engine. For the second case - by comparing the nature of changes in the starting characteristics acquired from the model with similar results reported in other works that addressed an inter-turn short circuit in the winding of the stator of the induction motor.

The study object is the induction traction motor for electric locomotives. The example selected for modeling was the traction motor STA-1200 (Ukraine), which is used on the $\mathrm{AC}$ electric locomotives of the DS-3 series. Its parameters are given in Table 1.

Table 1

Traction motor STA-1200 parameters

\begin{tabular}{|c|c|}
\hline Parameter & Parameter value \\
\hline Power, $\mathrm{kW}$ & 1,200 \\
\hline Effective linear voltage value, $\mathrm{V}$ & 1,870 \\
\hline Phase current effective value & 450 \\
\hline Power voltage rated frequency, $\mathrm{Hz}$ & 55.8 \\
\hline Power voltage frequency adjusting range, $\mathrm{Hz}$ & $0 \ldots 146$ \\
\hline Phase quantity & 3 \\
\hline Pole pair number & 3 \\
\hline Rated rotation frequency, rpm & 1,110 \\
\hline Shaft moment, $\mathrm{N} \cdot \mathrm{m}$ & 10,700 \\
\hline Efficiency $\eta, \%$ & 95.5 \\
\hline Power factor cos $\phi$ & 0.88 \\
\hline Magnetic circuit axial length $l_{\beta}, \mathrm{m}$ & 0.460 \\
\hline Stator turn length $l_{s}, \mathrm{~m}$ & 1.92 \\
\hline Rotor turn length $l_{r}, \mathrm{~m}$ & 0.465 \\
\hline Stator turn quantity $w_{s}$ & 48 \\
\hline Stator outer diameter $r_{s}, \mathrm{~m}$ & 0.51 \\
\hline Rotor outer diameter $r_{r}, \mathrm{M}$ & 0.506 \\
\hline
\end{tabular}

All other traction engine parameters required to build a model were calculated below.

\section{Results of studying the induction traction motor operation}

\section{1. A mathematical model of the induction traction} motor

Underlying a mathematical model of the three-phase IM is a mathematical model of the three-phase electric machine in the braked coordinate system whose axes $\alpha, \beta, \gamma[24,25]$ are combined with the axes of stator phases $A, B, C$. This system, in order to take into consideration losses in the magnetic circuit, is supplemented with the active resistances of the magnetization circuit $r_{\mu}$, enabled in each phase in parallel to the main inductances $L_{\mu}$ (an analogy with the $T$-shaped circuit replacement of the induction electric machine) (Fig. 1). 


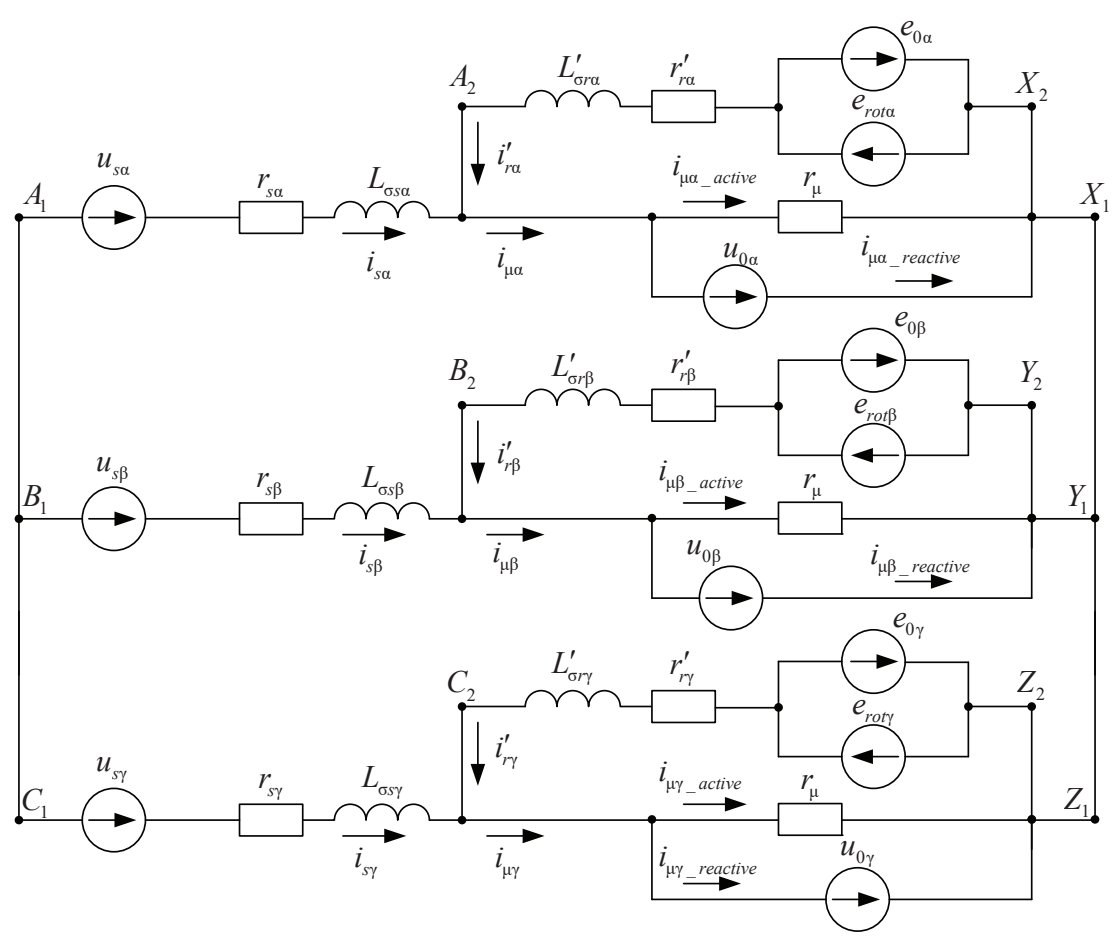

Fig. 1. Scheme of generalized induction machine in the "braked coordinates"

The equations of the IM electromagnetic processes are given in system (1) [25]. The following conventional assumptions regarding a generalized electric machine are accepted:

- each of the three stator windings creates a sinusoidal distributed magnetomotive force (MMF) in a smooth gap;

- the saturation coefficient of the magnetic circle is unchanged.

$$
\left\{\begin{array}{l}
u_{s \alpha}=r_{s \alpha} \cdot i_{s \alpha}+\frac{d\left(L_{\sigma s \alpha} \cdot i_{s \alpha}\right)}{d t}+u_{0 \alpha} ; \\
u_{s \beta}=r_{s \beta} \cdot i_{s \beta}+\frac{d\left(L_{\sigma s \beta} \cdot i_{s \beta}\right)}{d t}+u_{0 \beta} ; \\
u_{s \gamma}=r_{s \gamma} \cdot i_{s \gamma}+\frac{d\left(L_{\sigma s \gamma} \cdot i_{s \gamma}\right)}{d t}+u_{0 \gamma} ; \\
0=e_{0 \alpha}-e_{r o t \alpha}-\frac{d\left(L_{\sigma r \alpha}^{\prime} \cdot i_{r \alpha}\right)}{d t}-r_{r \alpha}^{\prime} \cdot i_{r \alpha} ; \\
0=e_{0 \beta}-e_{r o t \beta}-\frac{d\left(L_{\sigma r \beta}^{\prime} \cdot i_{r \beta}\right)}{d t}-r_{r \beta}^{\prime} \cdot i_{r \beta} ; \\
0=e_{0 \gamma}-e_{r o t \gamma}-\frac{d\left(L_{\sigma r \gamma}^{\prime} \cdot i_{r \gamma}\right)}{d t}-r_{r \gamma}^{\prime} \cdot i_{r \gamma},
\end{array}\right.
$$

where $u$ is the voltage;

$i$ - current;

$t$ - time;

$r$ - active resistance;

$\psi$ - flux coupling;

$\omega_{r}$ - mechanical rotor rotation frequency;

$p$ - the number of pole pairs.

Lower indexes $\alpha, \beta, \gamma$ indicate belonging to the corresponding phase. The lower index $s$ indicates stator affiliation, the index $r$ indicates rotor affiliation, and the index $\mu$ is an affiliation to the magnetizing branch. The components of system (1) are given in detail in expressions (2) to (8).

Voltages on the clamps of the magnetizing branches (derivatives from the flux coupling via mutual induction) of phases [25]:

$$
\left\{\begin{array}{l}
u_{0 \alpha}=\frac{d \psi_{\mu \alpha}}{d t}=r_{\mu \alpha} \cdot\left[\left(i_{s \alpha}+i_{r \alpha}\right)-\frac{1}{2} \cdot\left(\begin{array}{c}
i_{s \beta}+i_{r \beta}+ \\
+i_{s \gamma}+i_{r \gamma}
\end{array}\right)-\frac{\Psi_{\mu \alpha}}{M}\right] \\
u_{0 \beta}=\frac{d \psi_{\mu \beta}}{d t}=r_{\mu \beta} \cdot\left[\left(i_{s \beta}+i_{r \beta}\right)-\frac{1}{2} \cdot\left(\begin{array}{c}
i_{s \alpha}+i_{r \alpha}+ \\
+i_{s \gamma}+i_{r \gamma}
\end{array}\right)-\frac{\Psi_{\mu \beta}}{M}\right] \\
u_{0 \gamma}=\frac{d \psi_{\mu \gamma}}{d t}=r_{\mu \gamma} \cdot\left[\left(i_{s \gamma}+i_{r \gamma}\right)-\frac{1}{2} \cdot\left(\begin{array}{l}
i_{s \alpha}+i_{r \alpha}+ \\
+i_{s \beta}+i_{r \beta}
\end{array}\right)-\frac{\psi_{\mu \gamma}}{M}\right] .
\end{array}\right.
$$

For the symmetrical mode of stator windings, the mutual inductances of the IM windings are equal and defined as [24]

$$
M=\frac{2}{3} \cdot L_{\mu},
$$

where $M$ is the mutual inductance of the IM rotor and stator windings phase at the coincidence of their axes or the inductance of the stator winding due to the main magnetic flux, calculated in the absence of currents in other stator phases and rotor windings (that is, from the part of the main magnetic flux created by the stator phase itself);

$L_{\mu}$ is the full inductance of the stator winding phase due to the main magnetic flux. It takes into consideration the presence of currents in other phases (the inductance from the part of the main magnetic flux created by the $M$ winding itself) and the inductance due to the part of the main flux created by two other stator windings.

Phase magnetization currents [25]: 


$$
\left\{\begin{array}{l}
i_{\mu \alpha}=i_{s \alpha}+i_{r \alpha}=\frac{2}{3} \cdot\left[\begin{array}{l}
\left(i_{s \alpha}-\frac{1}{2} \cdot\left(i_{s \beta}+i_{s \gamma}\right)\right)+ \\
+\left(i_{r \alpha}-\frac{1}{2} \cdot\left(i_{r \beta}+i_{r \gamma}\right)\right)
\end{array}\right]= \\
=i_{\mu \alpha \_a c t i v e}+i_{\mu \alpha_{\_} \text {reactive }} ; \\
i_{\mu \beta}=i_{s \beta}+i_{r \beta}=\frac{2}{3} \cdot\left[\begin{array}{l}
\left(i_{s \beta}-\frac{1}{2} \cdot\left(i_{s \alpha}+i_{s \gamma}\right)\right)+ \\
+\left(i_{r \beta}-\frac{1}{2} \cdot\left(i_{r \alpha}+i_{r \gamma}\right)\right)
\end{array}\right]= \\
=i_{\mu \beta \_a c t i v e}+i_{\mu \beta \_ \text {reactive }} ; \\
i_{\mu \gamma}=i_{s \gamma}+i_{r \gamma}=\frac{2}{3} \cdot\left[\begin{array}{l}
\left(i_{s \gamma}-\frac{1}{2} \cdot\left(i_{s \alpha}+i_{s \beta}\right)\right)+ \\
+\left(i_{r \gamma}-\frac{1}{2} \cdot\left(i_{r \alpha}+i_{r \beta}\right)\right)
\end{array}\right]= \\
=i_{\mu \gamma \_a c t i v e}+i_{\mu \gamma \_ \text {reactive }} \cdot
\end{array}\right.
$$

In expression (4), $i_{\mu \text { active }}$ and $i_{\mu \text { reactive }}$ are the active and reactive (inductive) components of the phase magnetization current, respectively. The active components of the phase magnetization current are determined from expressions given in [25]:

$$
\left\{\begin{array}{l}
i_{\mu \alpha \_a c t i v e}=\frac{u_{0 \alpha}}{r_{\mu \alpha}} ; \\
i_{\mu \beta \_ \text {active }}=\frac{u_{0 \beta}}{r_{\mu \beta}} ; \\
i_{\mu \gamma \_ \text {active }}=\frac{u_{0 \gamma}}{r_{\mu \gamma}} .
\end{array}\right.
$$

The magnetizing branch MMF [25]:

$$
\left\{\begin{array}{l}
e_{0 \alpha}=-u_{0 \alpha} \\
e_{0 \beta}=-u_{0 \beta} \\
e_{0 \gamma}=-u_{0 \gamma}
\end{array}\right.
$$

The rotor phase rotation MMF [25]:

$$
\left\{\begin{array}{l}
e_{r \alpha}=\frac{\left(\psi_{r \beta}-\psi_{r \gamma}\right) \cdot p \cdot \omega_{r}}{\sqrt{3}} ; \\
e_{r \beta}=\frac{\left(\psi_{r \gamma}-\psi_{r \alpha}\right) \cdot p \cdot \omega_{r}}{\sqrt{3}} ; \\
e_{r \gamma}=\frac{\left(\psi_{r \alpha}-\psi_{r \beta}\right) \cdot p \cdot \omega_{r}}{\sqrt{3}} .
\end{array}\right.
$$

The rotor phase flux coupling [25]:

$$
\left\{\begin{array}{l}
\psi_{r \alpha}=L_{r \alpha} \cdot i_{r \alpha}+\Psi_{\mu \alpha} ; \\
\psi_{r \beta}=L_{r \beta} \cdot i_{r \beta}+\Psi_{\mu \beta} ; \\
\psi_{r \gamma}=L_{r \gamma} \cdot i_{r \gamma}+\Psi_{\mu \gamma} .
\end{array}\right.
$$

The equation of the IM electromagnetic moment takes the following form [25]:

$$
M_{E M}=p \cdot \frac{L_{\mu}}{\sqrt{3}} \cdot M \cdot\left[\begin{array}{l}
\left(i_{s \alpha} \cdot i_{r \gamma}+i_{s \beta} \cdot i_{r \alpha}+i_{s \gamma} \cdot i_{r \beta}\right)- \\
-\left(i_{s \alpha} \cdot i_{r \beta}+i_{s \beta} \cdot i_{r \gamma}+i_{s \gamma} \cdot i_{r \alpha}\right)
\end{array}\right] .
$$

The equation of motion for an IM shaft at a single-mass mechanical part [24]:

$$
\frac{d \omega_{r}}{d t}=\frac{1}{J} \cdot\left(M-M_{C}\right)
$$

where $J$ is the moment of inertia of rotating bodies.

The angle of rotation of the IM rotor shaft [26]:

$$
\theta_{r}=\theta_{r 0}+\int_{0}^{t} \omega_{r} \cdot \mathrm{d} t
$$

where $\theta_{r 0}$ is the initial angular position of the IM rotor shaft, rad.

Expressions (1)-(3), and (10) demonstrate that the following parameters are necessary for ITM simulation: the active resistances of stator windings $\left(r_{s \alpha}, r_{s \beta}, r_{s \gamma}\right)$, the active resistance of the rotor $\left(r_{r \alpha}^{\prime}, r_{r \beta}^{\prime}, r_{r \gamma}^{\prime}\right)$, reduced to the stator windings, the active resistance of the magnetization circle $r_{\mu}$, the inductance of the scattering of stator windings $\left(L_{s \alpha}\right.$, $\left.L_{s \beta}, L_{s \gamma}\right)$ reduced to the stator windings $\left(L_{r \alpha}^{\prime}, L_{r \beta}^{\prime}, L_{r \gamma}^{\prime}\right)$, the full inductance of the magnetization circuit $L_{\mu}$, the moment of inertia $J$. The next stage of modeling was the calculation of these parameters.

We calculated the active resistances of stator windings $\left(r_{s \alpha}, r_{s \beta}, r_{s \gamma}\right)$, the active resistances of rotor windings $\left(r_{r \alpha}^{\prime}, r_{r \beta}^{\prime}, r_{r \gamma}^{\prime}\right)$, reduced to the stator windings, the inductance of stator windings scattering $\left(L_{s \alpha}, L_{s \beta}, L_{s \gamma}\right)$, the inductance of rotor windings scattering $\left(L_{r \alpha}^{\prime}, L_{r \beta}^{\prime}, L_{r \gamma}^{\prime}\right)$. reduced to the stator windings. Their values are given in Table 2.

Table 2

Parameters of the traction motor STA-1200 acquired from calculations

\begin{tabular}{|c|c|}
\hline Parameter & Parameter value \\
\hline Active resistance of stator winding $r_{s}, \mathrm{Ohm}$ & 0.0226 \\
\hline $\begin{array}{c}\text { Rotor winding active resistance reduced to } \\
\text { the stator winding, } r_{r}^{\prime}, \text { Ohm }\end{array}$ & 0.0261 \\
\hline Stator winding scattering inductance, $L_{s}, \mathrm{mGn}$ & 0.65 \\
\hline $\begin{array}{c}\text { Rotor winding scattering inductance reduced } \\
\text { to the stator winding, } L_{r}^{\prime}, \mathrm{mGn}\end{array}$ & 0.45 \\
\hline $\begin{array}{c}\text { Magnetization circuit full inductance } \\
L_{\mu}, \mathrm{mGn}\end{array}$ & 19.4336 \\
\hline Moment of inertia $\mathrm{J}, \mathrm{kg} \cdot \mathrm{m}^{2}$ & 39 \\
\hline
\end{tabular}
below.

The calculation of other parameters was carried out

5. 2. Calculating the value of $r_{\mu}$ while taking into consideration the saturation of the magnetic circle along the path of the main magnetic flux

When modeling, the issue is to properly set the value of $r_{\mu}$, the criterion of which is the correct value of losses in the ITM steel $\left(p_{s t}\right)$.

Since the correct value of $p_{s t}$ is not exactly known, its value was calculated based on the reference for the rated mode of ITM operation [25] 


$$
\begin{aligned}
& p_{s t} \leq \frac{P_{2}}{3} \cdot\left(\frac{1}{\eta}-1\right)= \\
& =\frac{1200}{3} \cdot\left(\frac{1}{0.955}-1\right)=56.545, \mathrm{~kW},
\end{aligned}
$$

where $P_{2}=1,200 \mathrm{~kW}$ is the power on the IM shaft (Table 1); $\eta=0.955$ is the IM efficiency.

Considering that under other equal conditions, the voltage on the terminals of the magnetization circuit $U_{0}$ almost does not depend on the value of $r_{\mu}$, since it is stabilized by large inductance, one can adjust the $r_{\mu}$ value in accordance with the required value of $p_{s t}$, using the following formula [25]

$$
r_{\mu}=\frac{3 \cdot U_{0}^{2}}{p_{s t}}=\frac{3 \cdot 1,624.43^{2}}{56,545}=140, \Omega
$$

The voltage $U_{0}$ was determined from the model in the absence of the resistance $r_{\mu}$. Additionally, when adjusting $r_{\mu}$, the current value of the IM stator phase was controlled.

Saturation of the magnetic circuit of the electric motor is an important factor affecting the ITM dynamic characteristics [28, 29]. To take the saturation into consideration, an approach based on the use of nonlinear coefficients was chosen. This approach, unlike the approach based on accounting for a change in the harmonic composition of voltages and currents, does not require a priori knowledge of the quantitative characteristics of harmonic spectra.

The authors of $[27,28]$, in order to take into consideration the saturation for each phase and the equation of an ITM electromagnetic torque, apply the dependence of the main inductance as the function of the amplitude of the representing vector of the flux coupling of mutual inductance $L_{\mu}=f\left(\psi_{\mu \Sigma m}\right)$. The total flux coupling is derived from the following expressions

$$
\psi_{\mu \Sigma m}=\sqrt{\psi_{\mu x}^{2}+\psi_{\mu y}^{2}},
$$

where $\psi_{\mu x}$ and $\psi_{\mu y}$ are the amplitudes of projections of the representing vector of flux coupling onto the orthogonal axes of coordinates $X$ and $Y$.

For the three-phase "braked coordinates", these projections were derived from the flux coupling of phase magnetization [25]

$$
\begin{aligned}
& \psi_{\mu x}=\frac{2}{3} \cdot\left(\psi_{\mu \alpha}+\psi_{\mu \beta} \cdot \cos \left(-\frac{2 \cdot \pi}{3}\right)+\psi_{\mu \gamma} \cdot \cos \left(\frac{2 \cdot \pi}{3}\right)\right) ; \\
& \psi_{\mu \nu}=\frac{2}{3} \cdot\left(\psi_{\mu \alpha}+\psi_{\mu \beta} \cdot \sin \left(-\frac{2 \cdot \pi}{3}\right)+\psi_{\mu \beta} \cdot \sin \left(\frac{2 \cdot \pi}{3}\right)\right) .
\end{aligned}
$$

To simplify modeling, when accounting for these inductances as the functions of flux coupling and flux coupling are expressed in relative units. The instantaneous value of the full inductance of the stator winding phase in relative units [25] is

$$
L_{\mu}^{*}=\frac{L_{\mu}}{\sqrt{2} \cdot L_{\mu n o m}},
$$

where $L_{\mu}$ is the instantaneous value of the full inductance of the stator winding phase; $L_{\mu n o m}$ is the rated value of the full inductance of the stator winding phase.
The instantaneous value of the representing vector of flux coupling [25] is

$$
\psi_{\mu \Sigma}^{*}=\frac{\left|\psi_{\mu \Sigma}\right|}{\sqrt{2} \cdot \psi_{\mu \Sigma n o m}},
$$

where $\left|\psi_{\mu \Sigma}\right|$ is the module of the instantaneous value of flux coupling; $\psi_{\mu \Sigma \text { nom }}$ is the rated value of flux coupling.

The dependence of the instantaneous value of the full inductance of the stator winding phase in relative units on the instantaneous value of flux coupling is shown in Fig. 2.

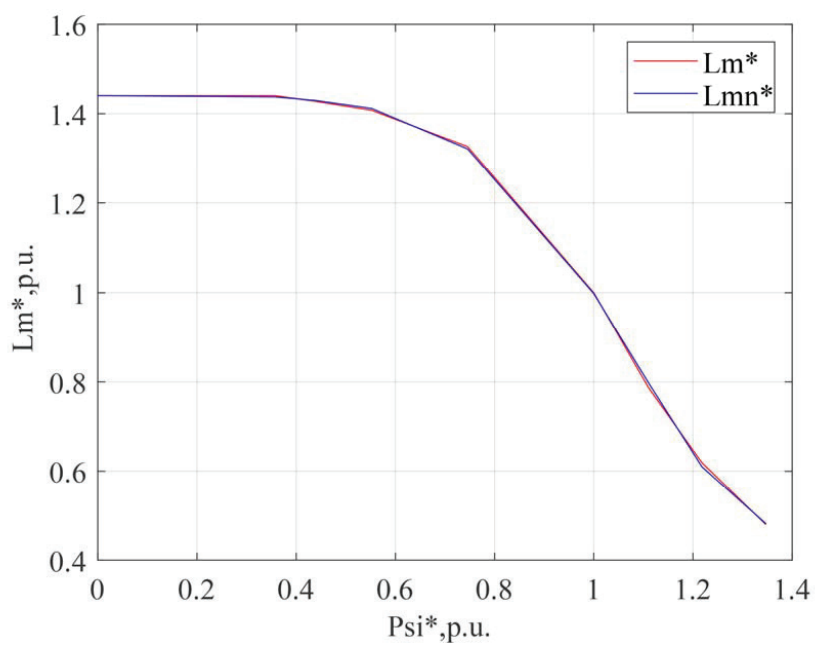

Fig. 2. Dependence of the instantaneous value of the stator winding phase full inductance in relative units $\left(\mathrm{Lm}^{*}\right)$ on the instantaneous flux coupling value ( $\left.\mathrm{Psi}^{*}\right)$ and its polynomial approximation $(\mathrm{Lmn} *)$

We have performed the polynomial approximation of the dependence of the instantaneous value of the full inductance of stator winding phase in relative units on the instantaneous value of the main magnetic flux (Fig. 2). Fig. 2 demonstrates that the result of approximation has high convergence with the values of the complete inductance of the stator winding phase.

5. 3. Developing an algorithm for taking into consideration a change in the parameters of the electric motor when changing the geometrical dimensions of its windings

The occurrence of asymmetry of the windings could be caused, for example, by the inter-turn short circuit of the stator's windings. At an inter-turn short circuit, there is a short circuit of one or more turns of the winding. That is the number of intact turns decreases. Study [26] shows a relationship between the geometric dimensions of the windings and the inductances of scattering and mutual inductances. The examined traction motor is an implicit-pole machine. The relationship between the mutual inductances of stator windings and their geometric dimensions for an implicit pole machine is calculated using the following expression [26]

$$
L_{i j}^{s s}=L_{i j \mu}^{s s},
$$

where 


$$
L_{i j \mu}^{s s}=l_{\beta} \cdot Z_{i}^{s} \cdot Z_{j}^{s} \cdot \frac{\pi}{p^{2}} \cdot \frac{r_{r}^{3}}{g} \cdot \mu,
$$

where $l_{\beta}$ is the air gap axial length;

$Z^{S}=w / l_{s}$ - the linear density of the current layer conductor;

$w$ - the number of a winding's turns;

$l_{s}$ - the stator winding length;

$g=r_{s}-r_{r}-$ the radial value of an air gap;

$r_{s}$ - the stator radius;

$r_{r}-$ the rotor radius;

$\mu$ - the vacuum magnetic permeability;

$p$ - the number of pole pairs.

The upper indices indicate belonging to the stator $(s)$ or rotor $(r)$ winding; the lower indexes indicate phase belonging $(a, b$, or $c)$.

The relationship between the mutual inductances of rotor windings and their geometric dimensions in the machine is calculated using the following expression [26]

$$
L_{i j}^{r r}=L_{i j \mu}^{r r},
$$

where

$$
L_{i j \mu}^{r r}=l_{\beta} \cdot Z_{i}^{r} \cdot Z_{j}^{r} \cdot \frac{\pi}{p^{2}} \cdot \frac{r_{r}^{3}}{g} \cdot \mu .
$$

The linear density of the conductors of the current layer of the rotor was determined from the following expression [27]

$$
Z^{r}=\frac{Z_{2} \cdot \sqrt{2}}{2 \cdot \pi \cdot r_{r}},
$$

where $Z_{2}$ is the number of rotor rods.

The relationship between the mutual inductances of the stator and rotary windings and their geometric dimensions in the machine is calculated using the following expression [26]

$$
\left\{\begin{array}{l}
L_{\alpha \alpha}^{s r}=L_{\alpha \alpha}^{r s}=L_{\alpha \alpha \mu}^{s r} \cdot \cos p \cdot \theta, \\
L_{\beta \beta}^{s r}=L_{\beta \beta}^{s s}=L_{\beta \beta \mu}^{s r} \cdot \cos p \cdot \theta, \\
L_{\gamma \gamma}^{s r}=L_{\gamma \gamma}^{s s}=L_{\gamma \mu}^{s r} \cdot \cos p \cdot \theta, \\
L_{\alpha \beta}^{s r}=L_{\beta \alpha}^{s s}=L_{\alpha \beta \mu}^{s r} \cdot \cos p \cdot\left(\theta+\frac{2 \cdot \pi}{3 \cdot p}\right), \\
L_{\alpha \gamma}^{s r}=L_{\gamma \alpha}^{s s}=L_{\alpha \gamma \mu}^{s r} \cdot \cos p \cdot\left(\theta-\frac{2 \cdot \pi}{3 \cdot p}\right), \\
L_{\beta \alpha}^{s r}=L_{\alpha \beta}^{r s}=L_{\beta \alpha \mu}^{s r} \cdot \cos p \cdot\left(\theta-\frac{2 \cdot \pi}{3 \cdot p}\right), \\
L_{\beta \gamma}^{s r}=L_{\beta \gamma}^{r s}=L_{\beta \gamma \mu}^{s s} \cdot \cos p \cdot\left(\theta+\frac{2 \cdot \pi}{3 \cdot p}\right), \\
L_{\gamma \alpha}^{s r}=L_{\alpha \gamma}^{r s}=L_{\gamma \alpha \mu}^{s r} \cdot \cos p \cdot\left(\theta+\frac{2 \cdot \pi}{3 \cdot p}\right), \\
L_{\gamma \beta}^{s r}=L_{\beta \gamma}^{s s}=L_{\beta \mu \mu}^{s r} \cdot \cos p \cdot\left(\theta-\frac{2 \cdot \pi}{3 \cdot p}\right),
\end{array}\right.
$$

where

$$
L_{i j \mu}^{s r}=l_{\beta} \cdot Z_{i}^{s} \cdot Z_{j}^{r} \cdot \frac{\pi}{p^{2}} \cdot \frac{r_{r}^{3}}{g} \cdot \mu .
$$

Then the mutual inductances for each phase take the following form

$$
\left\{\begin{array}{l}
M_{\alpha}=L_{\alpha \beta}^{s s}+L_{\alpha \gamma}^{s s}+L_{\alpha \beta}^{r r}+L_{\alpha \gamma}^{r r}+L_{\alpha \alpha}^{s r}+L_{\alpha \beta}^{s r}+L_{\alpha \gamma}^{s r}, \\
M_{\beta}=L_{\beta \alpha}^{s s}+L_{\beta \gamma}^{s s}+L_{\beta \alpha}^{r r}+L_{\beta \gamma}^{r r}+L_{\beta \beta}^{s r}+L_{\beta \alpha}^{s r}+L_{\beta \gamma}^{s r}, \\
M_{\gamma}=L_{\gamma \alpha}^{s s}+L_{\gamma \beta}^{s s}+L_{\gamma \alpha}^{r r}+L_{\gamma \beta}^{r r}+L_{\gamma \gamma}^{s r}+L_{\gamma \alpha}^{s r}+L_{\gamma \beta}^{s r} .
\end{array}\right.
$$

Then the complete inductance of the magnetizing branch is

$$
\begin{aligned}
& L_{\mu}=L_{\alpha \beta}^{s s}+L_{\alpha \gamma}^{s s}+L_{\beta \gamma}^{s s}+L_{\alpha \beta}^{r r}+L_{\alpha \gamma}^{r r}+L_{\beta \gamma}^{r r}+L_{\alpha \alpha}^{s r}+ \\
& +L_{\beta \beta}^{s r}+L_{\gamma \gamma}^{s r}+L_{\alpha \beta}^{s r}+L_{\alpha \gamma}^{s r}+L_{\beta \alpha}^{s r}+L_{\beta \gamma}^{s r}+L_{\gamma \alpha}^{s r}+L_{\gamma \beta}^{s r} .
\end{aligned}
$$

When no symmetry was set, the value of the active resistance of the damaged winding was found on the basis of the following considerations. The active resistance of the winding is

$$
r_{s}=k_{r} \cdot \rho_{\theta} \cdot \frac{l_{\text {mean }} \cdot w}{q_{\text {e.c. }} \cdot n_{\text {e.c. }} \cdot a},
$$

where $k_{r}$ is the coefficient of an increase in the active resistance of the winding phase due to the effect of the current displacement effect;

$\rho_{\theta}$ - the specific resistance of the material at estimated temperature;

$l_{\text {mean }}$ - the mean length of a winding turn;

$w$ - the number of a winding's turns;

$q_{\text {e.c. }}$ - the cross-sectional area of the elementary conductor;

$n_{e . c}$ - the number of elementary conductors;

$a$ - the number of parallel branches in a stator phase.

The winding scattering inductance is

$$
L_{\sigma s}=\frac{\left(w^{\prime}\right)^{2} \cdot \mu_{0} \cdot S}{l_{s}},
$$

where $S$ is the area of the cross-section of the conductor.

Since both active resistance and the inductance of winding scattering are the functions of the number of turns, they were calculated for a damaged winding according to the following expressions

$$
\begin{aligned}
& r_{s_{-} \text {defect }}=r_{s} \cdot \frac{\omega^{\prime}}{\omega}, \\
& L_{\sigma s_{-} \text {defect }}=L_{\sigma s} \cdot\left(\frac{\omega^{\prime}}{\omega}\right)^{2},
\end{aligned}
$$

where $w^{\prime}$ is the number of turns in a winding.

It follows from equations (27) that when setting an asymmetric mode, expression (3) is not to be used. Therefore, in expressions (2), the value of the mutual inductance $(M)$, which, under a symmetric mode, is the same for all three phases, has been replaced by those appropriate to a system of equations (26).

The active resistance and the scattering inductance of the damaged stator winding were taken into consideration by substitution into equation (1) for the damaged phase.

5. 4. A simulation model of the traction induction motor

The simulation model of the traction induction motor has been implemented in the MATLAB programming environment (Fig. 3). 

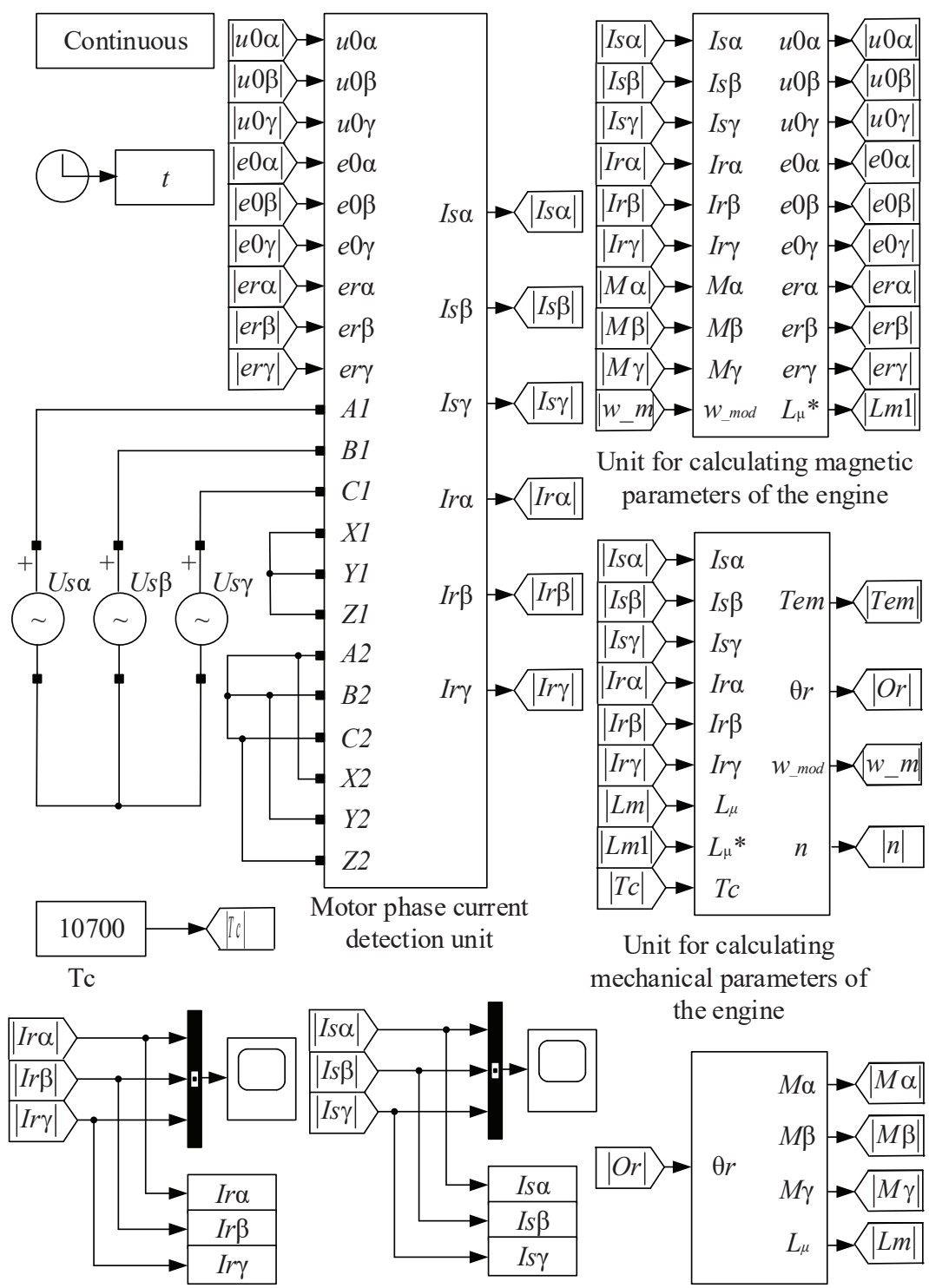

Unit for calculating mechanical parameters of the engine

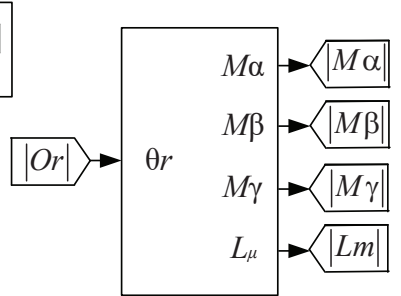

Unit for calculating the mutual inductances and complete inductance of the circuit of

magnetism
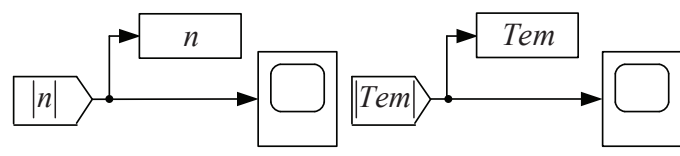

Fig. 3. Simulation model of the induction traction motor

It consists of four units. "Motor phase current detection unit" implements equation system (1). It is implemented in the software package Simscape/Electrical/Specialized Power Systems. The equations from system (1) were implemented with the help of elements such as resistors, inductance, controlled voltage sources, and controlled current sources.

All other units were implemented in the Simulink package in the form of structural schemes. "Unit for calculating magnetic parameters of the engine" implements equations (2), (6) to (8), (14) to (18). "Unit for calculating mechanical parameters of the engine" implements equations (9) to (11), "Unit for calculating the mutual inductances and complete inductance of the circuit of magnetism" implements equations (19) to (27). The traction motor power supply employs the system of symmetrical phase voltages
$U_{s \alpha}, U_{s \beta}$, and $U_{s \gamma}$, whose amplitudes and frequencies correspond to the rated mode.

The static resistance of the motor is set constant, its value corresponds to the rated load.

\section{5. Simulation results}

The diagrams of stator currents (Fig. 4), stator currents under a steady mode (Fig. 5), rotor currents (Fig. 6), rotor currents under a steady mode (Fig. 7), electromechanical torque (Fig. 8), and motor shaft rotation speed (Fig. 9) were acquired from the simulated model for the stator intact windings.

The diagrams of stator currents under a steady mode (Fig. 5) were used to determine the effective value of stator currents. It was $429 \mathrm{~A}$. 


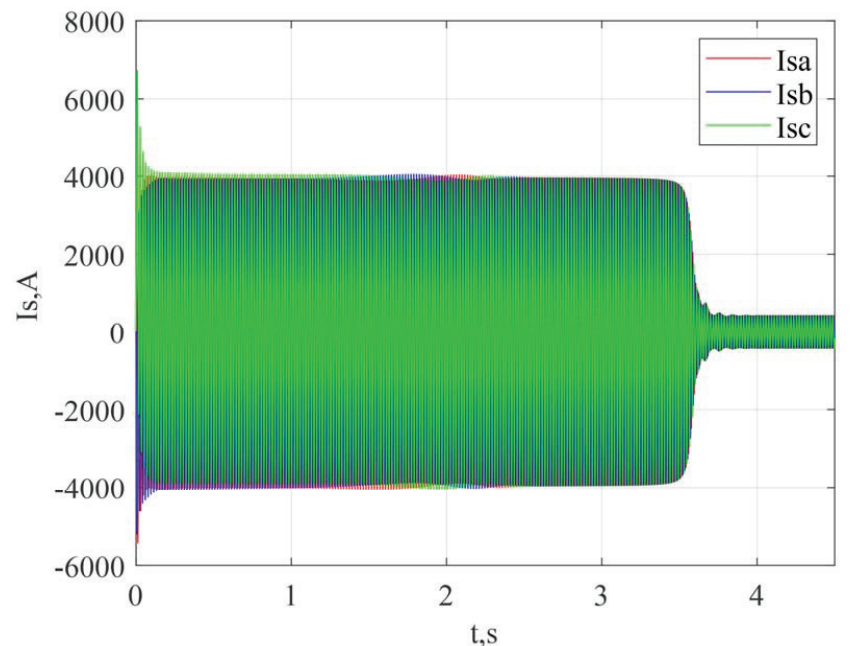

Fig. 4. Diagrams of stator currents of an intact motor

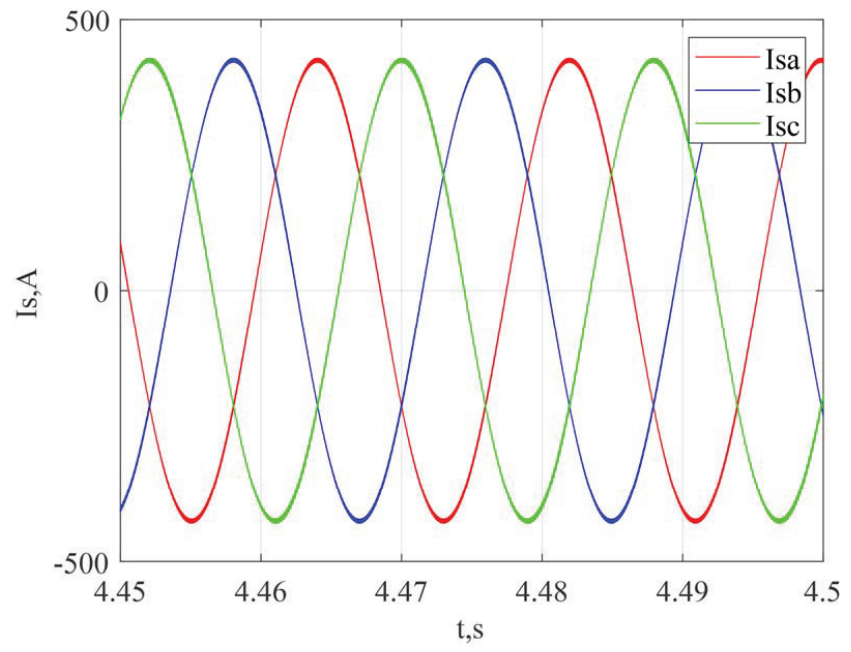

Fig. 5. Diagrams of stator currents of an intact motor under a steady mode

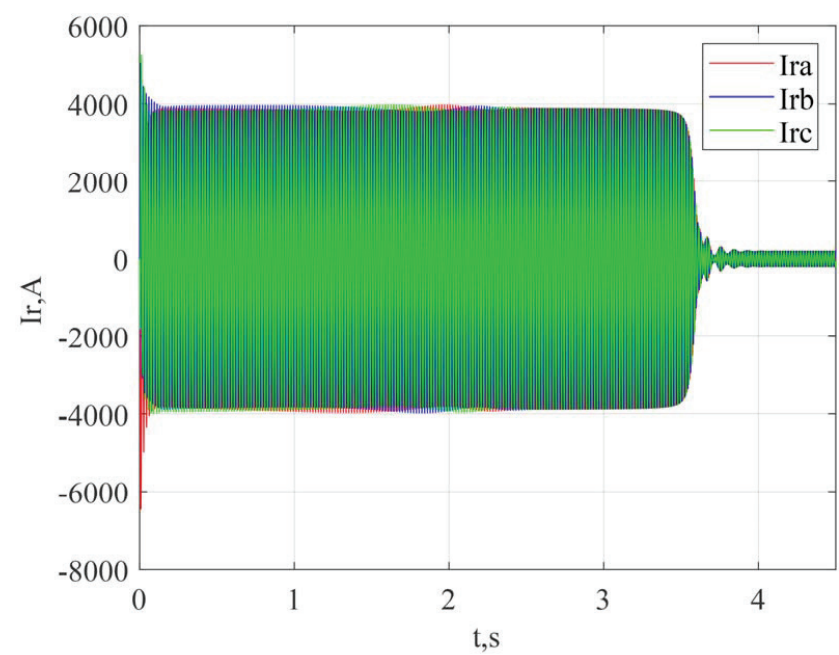

Fig. 6. Diagrams of rotor currents in an intact motor

The value of torque under a steady mode was $10,700 \mathrm{~N} \cdot \mathrm{m}$ (Fig. 8), the value of the shaft rotation speed under a steady mode $-1,112.36 \mathrm{rpm}$ (Fig. 9), the transition process time $-4.02 \mathrm{~s}$ (Fig. 8, 9).

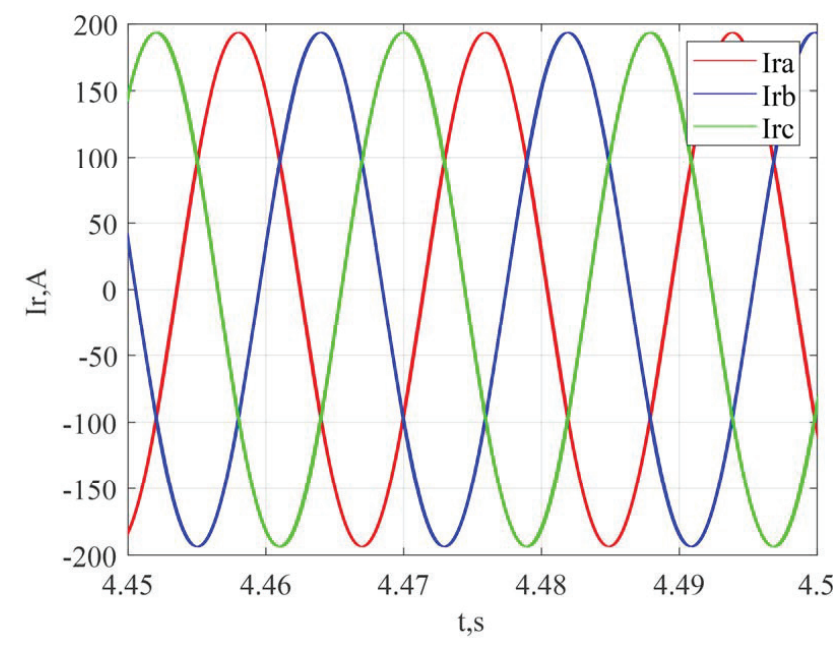

Fig. 7. Diagrams of rotor currents in an intact motor under a steady mode

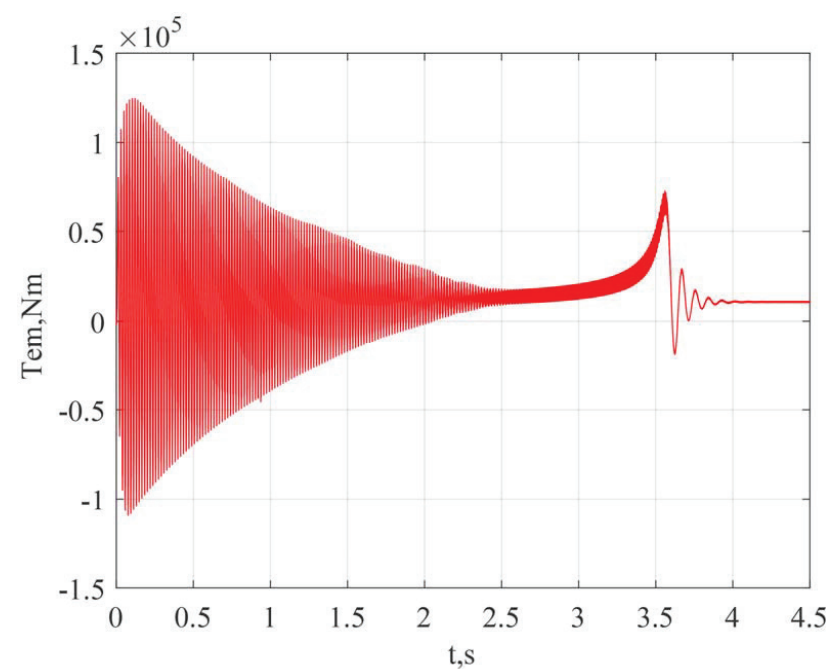

Fig. 8. Diagram of electromechanical torque in an intact motor

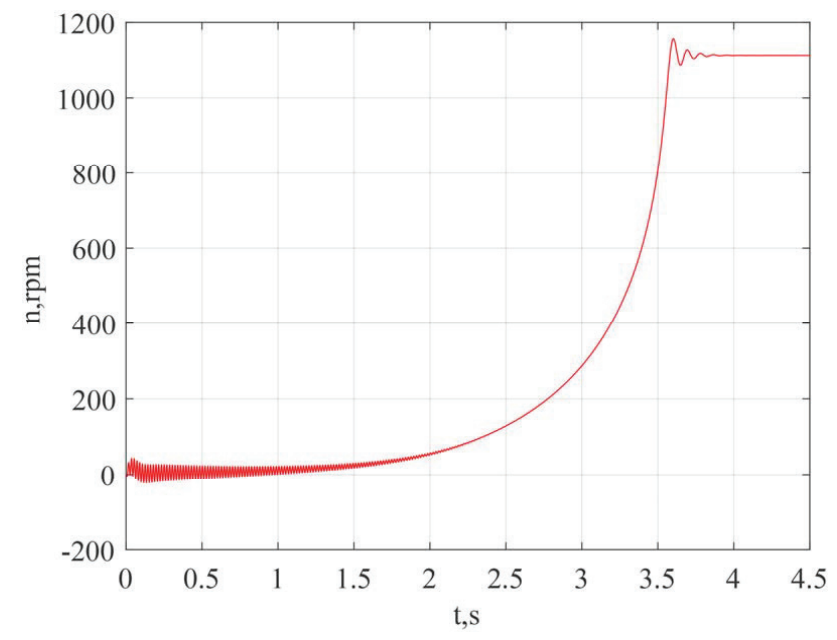

Fig. 9. Diagram of the shaft rotation speed in an intact motor

When setting the asymmetrical mode of stator windings, it was suggested that there was an inter-turn short 
circuit in the winding phase $A$. At the same time, it was believed that 5 turns of the windings were short-circuited. Formulas (30), (31) were used to calculate the active resistance and the inductance of scattering in the stator winding phase $A$. Appropriate changes were introduced in the "Unit for determining the phase currents of the motor". In the "Unit for calculating the mutual inductance and complete inductance of the magnetizing branch", the number of stator windings of phase $A$ was reduced by 5 . As a result, we acquired time charts for the stator (Fig. 10,11) and rotor currents (Fig. 12, 13), as well as the diagrams of electromechanical torque (Fig. 14, 15) and a diagram of the motor shaft rotation speed (Fig. 16).

The effective value of the stator current for the damaged phase $A$ was $462 \mathrm{~A}$, for the intact phases $B$ and $C-431$ A (Fig. 11). Under a steady mode, torque pulsations appeared on the motor shaft, the frequency of which is equal to the double frequency of the power voltage $-111.2 \mathrm{~Hz}$. Their maximum value was $11,2300 \mathrm{~N} \cdot \mathrm{m}$, the minimum value was $93,100 \mathrm{~N} \cdot \mathrm{m}$ (Fig. 15). The transition process time was $2.85 \mathrm{~s}$.

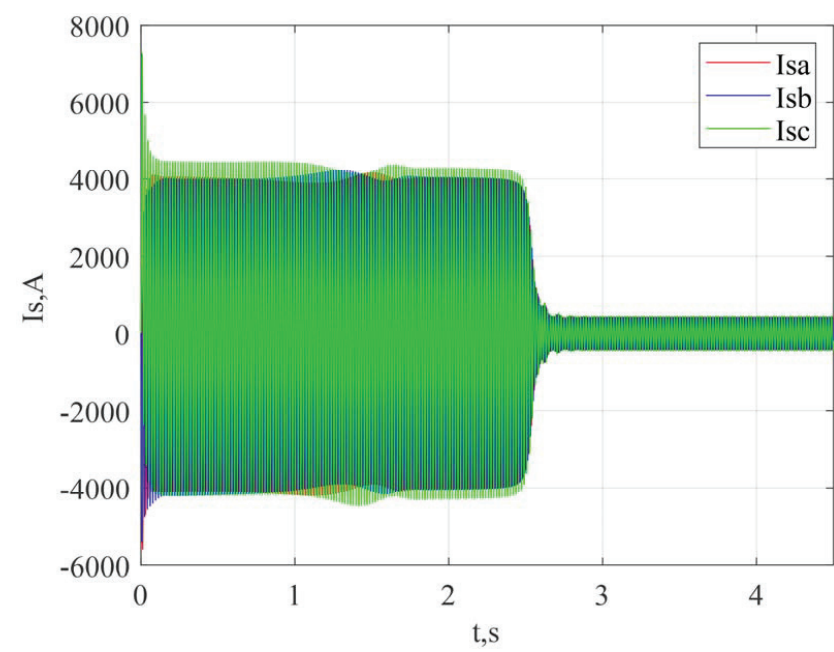

Fig. 10. Diagrams of stator currents in a damaged motor

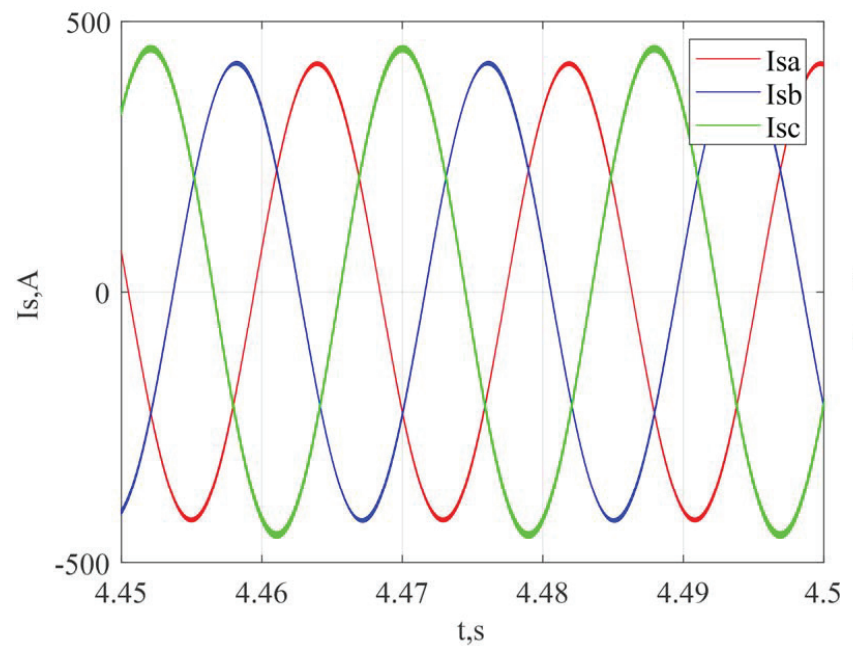

Fig. 11. Diagrams of stator currents in a damaged motor under a steady mode

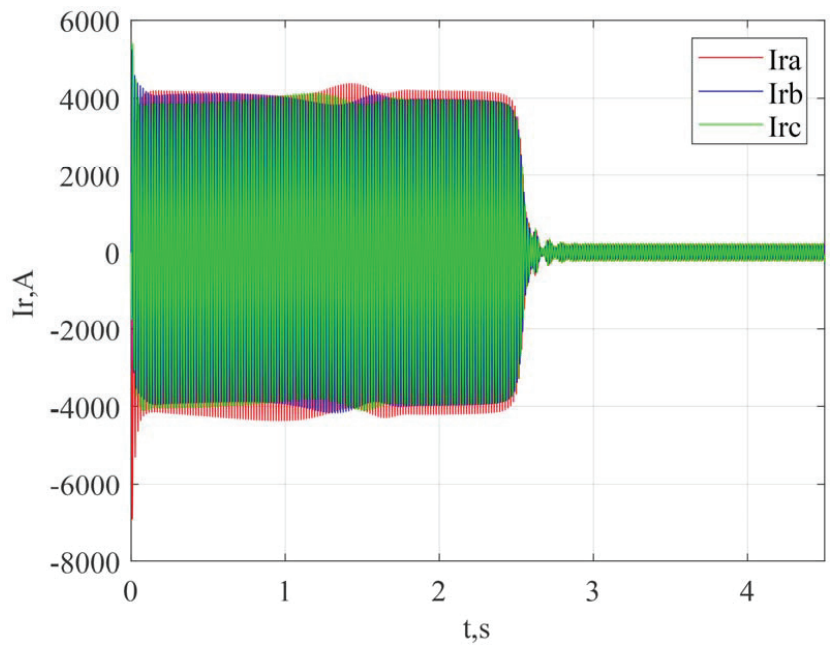

Fig. 12. Diagrams of rotor currents in an intact motor

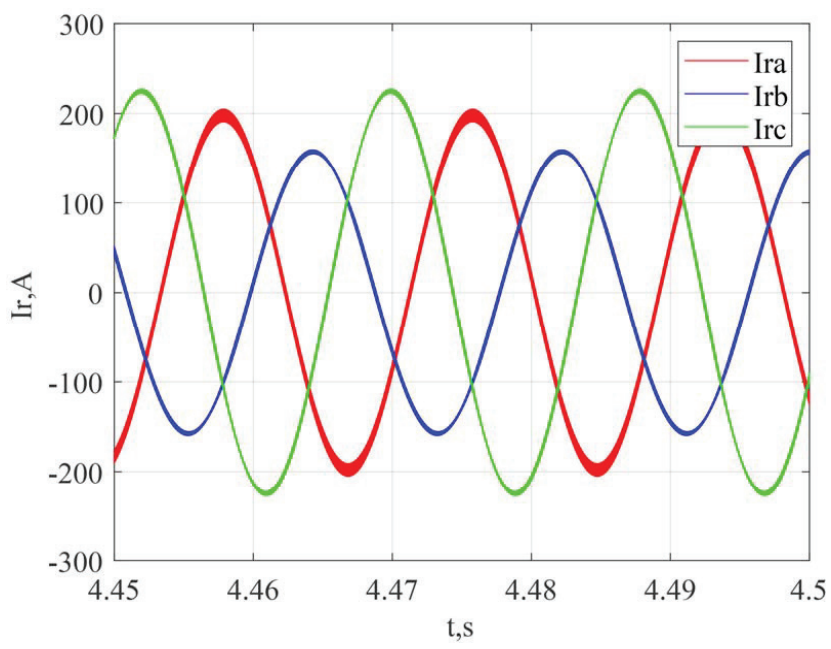

Fig. 13. Diagrams of rotor currents in a damaged motor under a steady mode

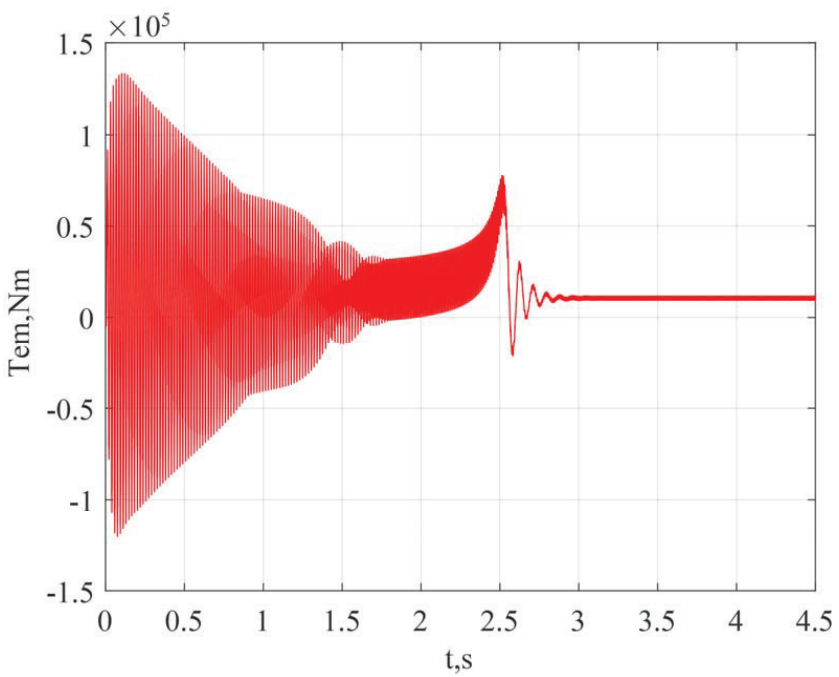

Fig. 14. Diagram of the torque electromechanical moment in a damaged engine 


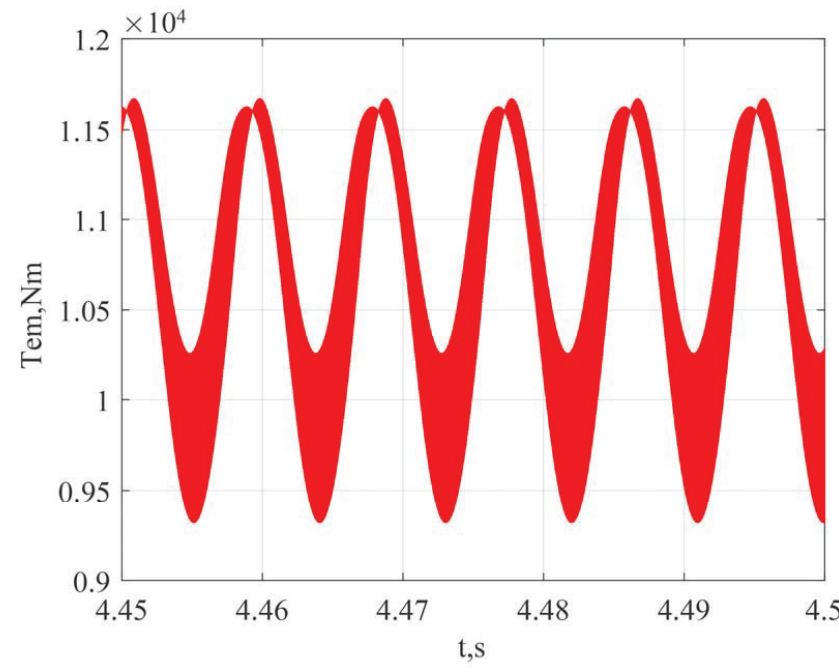

Fig. 15. Diagram of the torque electromechanical moment under a steady mode of the damaged engine

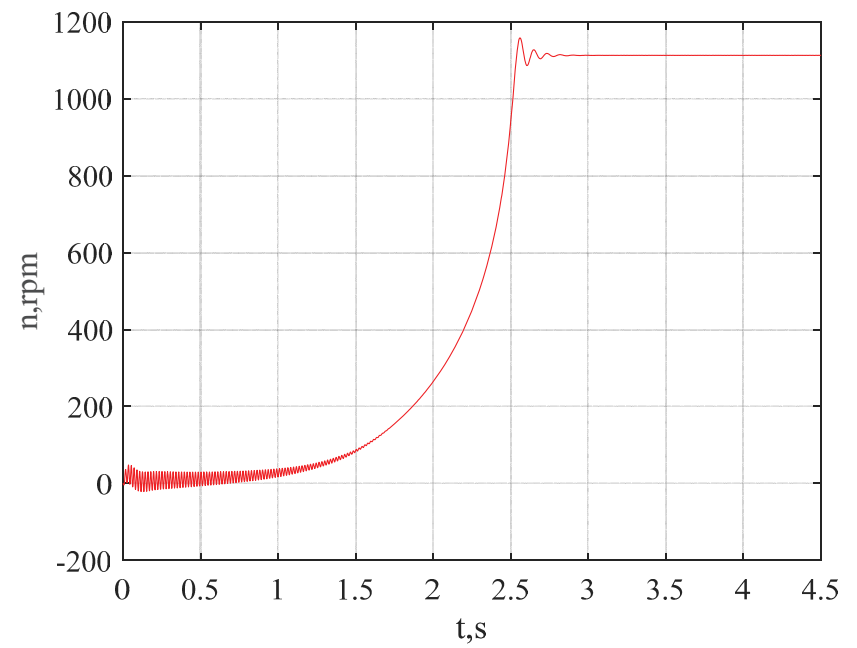

Fig. 16. Diagram of the shaft rotation speed in a damaged engine

\section{Discussion of results of modeling the induction traction motor}

The accuracy of modeling an intact induction traction motor could be estimated by comparing the estimated values of stator currents, the motor shaft rotation frequency, and the torque for the rated steady mode with its specification values. The error in determining the stator currents was $4.67 \%$ (Fig. 5 ), the motor shaft speed of rotation $0.21 \%$ (Fig. 9), torque $-0 \%$ (Fig. 8).

The high degree of reliability when determining the model-based stator currents is explained by the fact that the calculation of the active resistance of the magnetization circuit was carried out taking into consideration the specification value of the motor efficiency.

Accounting for the saturation of the induction motor magnetic circuit has made it possible to clarify the parameters of the electric motor under the transition and steady modes.

In other words, we can consider the simulation model of an induction traction engine adequate with a high degree of reliability. Note that the proposed model did not take into consideration mechanical losses that will be accounted for in further studies.

The algorithm for managing the asymmetric mode of stator's windings (19) to (26), (29) to (31) was proposed based on the procedure given in study [26]. The proposed algorithm was implemented on a simulation model. Based on the procedure reported in study [26] the asymmetric mode of stator windings was implemented in work [16]. However, in work [16], when determining the mutual inductances of phases, changes in the local mutual inductances of the stator and rotor windings were taken into consideration. It did not take into consideration the local mutual inductances caused by the mutual connection between the stator and rotor windings, which is a function of the angle of rotation of the motor shaft. We took into consideration this drawback, which has made it possible to obtain more accurate characteristics of the electric motor with asymmetric stator windings.

We have analyzed the time charts of stator and rotor currents (Fig. 10-13), the diagrams of the electromagnetic moment (Fig. 14, 15), the speed of rotation of the motor shaft (Fig. 16) for the damaged induction motor. The analysis revealed that the nature of change in these parameters does not contradict the data given in works [29,30], which studied the inter-turn short circuit in the stator windings of the induction motor.

Investigating the operation of an engine with asymmetric stator windings has demonstrated that a given mode is characterized by torque pulsations under a steady mode (Fig. 15), as well as the imbalance of stator phase currents (Fig. 11). The pulsation frequency of torque is equal to the double power voltage frequency. The pulsation coefficient of the torque was

$$
\begin{aligned}
& k_{p T}=\frac{T_{e m_{\_} \max }-T_{e m_{\_} \min }}{2 \cdot T_{\text {em_nom }}} \cdot 100 \%= \\
& =\frac{11,250-9,710}{2 \cdot 10,700} \cdot 100 \%=7.2 \% .
\end{aligned}
$$

The value for the maximum and minimum torque was determined from Fig. 14.

This indicator for a similar degree of damage to the stator winding in the induction electric motor, reported in $[29,30]$, was $6.85 \%$. The difference between the results of our modeling and those given in studies $[29,30]$ does not exceed $5 \%$.

The imbalance of the stator phase currents was

$$
\begin{aligned}
& k_{\text {mbal }}=\frac{I_{s_{-} \max }-I_{s_{\_} \min }}{2 \cdot I_{s_{-} \text {nom }}} \cdot 100 \%= \\
& =\frac{462-431}{2 \cdot 429} \cdot 100 \%=7.2 \% .
\end{aligned}
$$

The value of the maximum and minimum current of the stator was determined from Fig. 11; the rated value for the symmetrical mode - from Fig. 5.

A similar indicator for a similar degree of damage to the stator winding in the induction electric motor, given in studies [29,30], amounted to $7.55 \%$. The difference between the results of our modeling and those given in s $[29,30]$ does not exceed $5 \%$. 
The time of the transition process for a damaged engine (Fig. 14, 16) decreased, compared to the time of the transition process in an intact engine (Fig. 8, 9), by $26.7 \%$. This is due to the fact that in the damaged motor, due to a decrease in the number of intact windings, the mutual inductances of phases, the complete inductance of the magnetizing branch (19) to (27), the active resistance (30), and the inductance of scattering (31) in the damaged winding, decrease. The comparison of the transition process time for the damaged and intact engine given in studies [29,30] has shown that the transition time in the damaged engine decreased by $24.3 \%$. The difference between the results of our modeling and those reported in $[29,30]$ does not exceed $10 \%$.

However, the construction of the proposed model was based on the assumption about the independence of the values for the active resistances of the stator and rotor on temperature, which, in turn, is a function of the values of the corresponding phase currents. This factor imposes certain restrictions on the application of the proposed model. To take into consideration this factor, additional research should be carried out. At the same time, we are aware of the difficulties associated with acquiring experimental data during the operation of an electric locomotive.

Some areas to advance this study are:

- to investigate the operation of the traction drive in an AC locomotive with induction traction motors;

- to examine the influence of electric locomotive operating modes (starting and braking of the train, the transition from one position of the controller of the driver to another, slipping, skidding) on the energy indicators of the traction drive with induction traction engines.

\section{Conclusions}

1. We have replaced, in the basic model of the induction motor, the mutual inductances with a controlled voltage source. The control signal for the voltage source is the derivative from the flux coupling of the magnetization circuit for time. This has subsequently made it possible to take into consideration the saturation of the magnetic circuit of the electric motor and account for a change in the mutual inductances of each phase when changing the geometry of one of the phases. At the same time, the electric part of the electric motor does not require structural changes.

2. Taking into consideration losses in steel by introducing the active resistance into the circle of magnetization, enabled in parallel to the controlled voltage source, has allowed the high accuracy of taking into consideration the losses in the electric motor in general, as well as obtaining the value of phase currents of the stator with fairly high accuracy. This is explained by the fact that the calculation of the value for the active resistance of the magnetization circuit was carried out taking into consideration the specification value of the efficiency of the electric motor.

Accounting for the saturation of the magnetic circuit of the electric motor by multiplying the mutual inductances of phases and the complete inductance of the magnetization circuit by the relative inductance of the magnetization circuit as a function of the relative flux coupling has improved the dynamic properties of the model. At the same time, unlike the saturation consideration approach, using magnetized circuit inductance as a function of the current of the magnetization circuit, the ratio between the active and reactive components of the current of the magnetization circuit was not compromised.

3. When developing an algorithm for taking into consideration a change in the mutual inductances of the phases and the main inductance when changing the geometric dimensions of stator windings, only local mutual inductances of the stator and rotor windings were taken into consideration in a series of studies. Our proposed algorithm also took into consideration the local mutual inductances between the stator and rotor windings. That has made it possible to investigate with higher accuracy the operation of the induction motor with asymmetric stator windings.

4. When implementing the mathematical model in the MATLAB programming environment, the basic model was supplemented with a unit for calculating the mutual inductances of phases and the complete inductance of the magnetization circuit. That has made it possible, when managing the asymmetry of stator windings, not to change the structure of the simulation model. To this end, one should replace only the values for the active resistance and the inductance of the damaged phase, and the number of damaged turns in a winding.

5 . When testing the model for adequacy for an intact engine, we compared starting characteristics under a steady mode with specification values. Errors in measuring the speed of rotation of the motor shaft, the electromagnetic moment, and the phase currents of the stator in an intact motor under a steady mode, compared to the specification data for the electric motor, were $0.21 \%, 0 \%$, $4.67 \%$, respectively.

The nature of changes in the starting characteristics of the intact and damaged engines has revealed the following. The imbalance of phase currents in a damaged engine was $7.2 \%$. The pulsation coefficient was $7.2 \%$, the pulsation rate was equal to the doubled power voltage frequency. The time of the transition process in a damaged engine decreased by $26.7 \%$. The works that tackled the inter-turn short circuit of stator windings in an induction motor reported the following results. The imbalance of phase currents in a damaged engine was $6.85 \%$. The pulsation coefficient was $7.55 \%$, the pulsation rate was equal to the doubled power voltage frequency. The time of the transition process in a damaged engine decreased by $24.3 \%$. The difference between the results of our modeling and those given in other studies does not exceed $10 \%$. This indicates that the nature of their changes does not contradict the data reported in studies that tackled the inter-turn short circuit of stator windings in an induction motor.

\section{Acknowledgments}

We note that this study was made possible owing to funding from the Ministry of Education and Science of Ukraine within the research project "Improving the energy efficiency of railroad rolling stock based on resource-saving technologies and intelligent energy systems" (State Registration No. 0120U101912). 


\section{References}

1. Babyak, M., Keršys, R., Neduzha, L. (2020). Improving the Dependability Evaluation Technique of a Transport Vehicle. Proceedings of 24th International Scientific Conference. Transport Means 2020. Pt. II. Kaunas, 646-651.

2. Fomin, O. V. (2015). Increase of the freight wagons ideality degree and prognostication of their evolution stages. Scientific Bulletin of National Mining University, 3, 68-76. Available at: http://nv.nmu.org.ua/index.php/en/component/jdownloads/finish/54-03/ 8333-2015-03-fomin/0

3. Kabalyk, Y. (2016). Determination of Energy Loss in Power Voltage Inverters for Power Supply of Locomotive Traction Motors. Procedia Engineering, 165, 1437-1443. doi: https://doi.org/10.1016/j.proeng.2016.11.876

4. Kuznetsov, V., Lyubarskyi, B., Kardas-Cinal, E., Yeritsyan, B., Riabov, I., Rubanik, I. (2020). Recommendations for the selection of parameters for shunting locomotives. Archives of Transport, 56 (4), 119-133. doi: https://doi.org/10.5604/01.3001.0014.5650

5. Kolpakhchyan, P., Zarifian, A., Andruschenko, A. (2017). Systems Approach to the Analysis of Electromechanical Processes in the Asynchronous Traction Drive of an Electric Locomotive. Studies in Systems, Decision and Control, 67-134. doi: https:// doi.org/10.1007/978-3-319-51502-1_3

6. Vlas'evskii, S. V., Malysheva, O. A., Marinich, L. P. (2019). Estimation of the Realization of Traction Force on the Adhesion of AC Electric Locomotives with an Asynchronous and Collector Drives. 2019 International Science and Technology Conference "EastConf." doi: https://doi.org/10.1109/eastconf.2019.8725405

7. Bonnet, V. V., Loginov, A. Y., Prudnikov, A. Y., Bonnet, Y. V., Bonnet, M. V. (2020). Method for determining the power of squirrelcage induction motors. IOP Conference Series: Earth and Environmental Science, 421, 052009. doi: https://doi.org/10.1088/ $1755-1315 / 421 / 5 / 052009$

8. Prudnikov, A. Yu., Bonnet, V. V., Loginov, A. Yu. (2020). Method of diagnostics of the rotor eccentricity of an induction motor. Journal of Physics: Conference Series, 1515, 052030. doi: https://doi.org/10.1088/1742-6596/1515/5/052030

9. Khechekhouche, A., Cherif, H., Benakcha, A., Menacer, A., Chehaidia, S. E., Panchal, H. (2020). Experimental diagnosis of interturns stator fault and unbalanced voltage supply in induction motor using MCSA and DWER. Periodicals of Engineering and Natural Sciences, 8 (3), 1202-1216. Available at: http://pen.ius.edu.ba/index.php/pen/article/view/1058/607

10. Mirzaev, U., Abdurauf, A. (2021). Mathematical Model of an Asynchronous Motor in Full-Phase Operation. International Journal of Engineering and Information Systems (IJEAIS) ISSN, 5 (3), 10-14. Available at: https://ssrn.com/abstract=3815616

11. Atiyah, A., Sulc, B. (2020). Role of Asynchronous Motor Modelling in Driven Railway Wheelset Dynamical Simulation Model. 2020 21th International Carpathian Control Conference (ICCC). doi: https://doi.org/10.1109/iccc49264.2020.9257241

12. Diacenko, G. (2020). Rotor flux controller for induction machines considering main inductance saturation. Problemele Energeticii Regionale, 3 (47), 10-19. Available at: https://zenodo.org/record/4018933\#.YOVZPZj7SUk

13. Pal, R. S. C., Mohanty, A. R. (2021). A Simplified Dynamical Model of Mixed Eccentricity Fault in a Three-Phase Induction Motor. IEEE Transactions on Industrial Electronics, 68 (5), 4341-4350. doi: https://doi.org/10.1109/tie.2020.2987274

14. Nasir, B. A. (2020). An Accurate Iron Core Loss Model in Equivalent Circuit of Induction Machines. Journal of Energy, 2020, 1-10. doi: https://doi.org/10.1155/2020/7613737

15. Goolak, S., Tkachenko, V., Bureika, G., Vaičiūnas, G. (2021). Method of spectral analysis of traction current of AC electric locomotives. Transport, 35 (6), 658-668. doi: https://doi.org/10.3846/transport.2020.14242

16. Goolak, S., Gubarevych, O., Yermolenko, E., Slobodyanyuk, M., Gorobchenko, O. (2020). Mathematical modeling of an induction motor for vehicles. Eastern-European Journal of Enterprise Technologies, 2 (2 (104)), 25-34. doi: https://doi.org/10.15587/ 1729-4061.2020.199559

17. Zhang, R., Yin, Z., Du, N., Liu, J., Tong, X. (2021). Robust Adaptive Current Control of a 1.2 MW Direct-Drive PMSM for Traction Drives based on Internal Model Control with Disturbance Observer. IEEE Transactions on Transportation Electrification, 1-1. doi: https://doi.org/10.1109/tte.2021.3058012

18. Deryabin, E. I., Zhuravleva, L. A. (2020). Electric traction drive of an agricultural tractor. IOP Conference Series: Earth and Environmental Science, 548, 032037. doi: https://doi.org/10.1088/1755-1315/548/3/032037

19. Ferestade, I., Ahmadian, M., Molatefi, H., Moaveni, B., Bokaeian, V. (2020). Integrated sliding mode and direct torque controls for improving transient traction in high-speed trains. Journal of Vibration and Control, 27 (5-6), 629-650. doi: https:// doi.org/10.1177/1077546320932027

20. Liubarskyi, B., Petrenko, A., Shaida, V., Maslii, A. (2017). Analysis of optimal operating modes of the induction traction drives for establishing a control algorithm over a semiconductor transducer. Eastern-European Journal of Enterprise Technologies, 4 (8 (88)), 65-72. doi: https://doi.org/10.15587/1729-4061.2017.109179

21. Shavolkin, O., Shvedchykova, I. (2018). Forming of Current of the Single-Phase Grid Inverter of Local Combined Power Supply System with a Photovoltaic Solar Battery. 2018 IEEE 3rd International Conference on Intelligent Energy and Power Systems (IEPS). doi: https://doi.org/10.1109/ieps.2018.8559540 
22. Yatsko, S., Vashchenko, Y., Sidorenko, A., Lyubarskyi, B., Yeritsyan, B. (2019). Electrical transport with onboard energy storage. International Journal of Renewable Energy Research (IJRER), 9 (2), 848-858. Available at: https://www.ijrer.org/ijrer/index.php/ ijrer/article/view/9143/pdf

23. Shavolkin, O., Shvedchykova, I. (2020). Improvement of the multifunctional converter of the photoelectric system with a storage battery for a local object with connection to a grid. 2020 IEEE KhPI Week on Advanced Technology (KhPIWeek). doi: https:// doi.org/10.1109/khpiweek51551.2020.9250096

24. Pustovetov, M. Y. (2018). Approach to Computer Implementation of Mathematical Model of 3-Phase Induction Motor. IOP Conference Series: Materials Science and Engineering, 327, 022085. doi: https://doi.org/10.1088/1757-899x/327/2/022085

25. Pustovetov, M. Yu. (2016). Podhod k realizatsii na EVM matematicheskoy modeli asinhronnogo dvigatelya, prednaznachennoy dlya ispol'zovaniya v kachestve sostavnoy chasti modeley elektrotekhnicheskih kompleksov i sistem. Modelirovanie. Teoriya, metody i sredstva: Materialy 16-oy Mezhdunarodnoy nauchno-prakticheskoy konferentsii, posvyaschennoy 110-letiyu Yuzhno-Rossiyskogo gosudarstvennogo politekhnicheskogo universiteta (NPI) imeni M.I. Platova. Novocherkassk, 332-345. Available at: https:// www.elibrary.ru/item.asp?id=27557409

26. Goolak, S., Gerlici, J., Tkachenko, V., Sapronova, S., Lack, T., Kravchenko, K. (2019). Determination of Parameters of Asynchronous Electric Machines with Asymmetrical Windings of Electric Locomotives. Communications - Scientific Letters of the University of Zilina, 21 (2), 24-31. doi: https://doi.org/10.26552/com.c.2019.2.24-31

27. Carbonieri, M., Bianchi, N. (2020). Induction Motor Rotor Losses Analysis Methods Using Finite Element. 2020 IEEE International Conference on Industrial Technology (ICIT). doi: https://doi.org/10.1109/icit45562.2020.9067209

28. Accetta, A., Cirrincione, M., Pucci, M., Sferlazza, A. (2020). Space-vector state dynamic model of SynRM considering selfand cross-saturation and related parameter identification. IET Electric Power Application, 14 (14), 2798-2808. doi: https:// doi.org/10.1049/iet-epa.2020.0504

29. Zagirnyak, M., Kalinov, A., Melnykov, V., Stakhiv, P. (2016). Fault-tolerant control of an induction motor with broken stator electric circuit. 2016 Electric Power Networks (EPNet). doi: https://doi.org/10.1109/epnet.2016.7999372

30. Zagirnyak, M., Kalinov, A., Melnykov, V. (2017). Variable-frequency electric drive with a function of compensation for induction motor asymmetry. 2017 IEEE First Ukraine Conference on Electrical and Computer Engineering (UKRCON). doi: https:// doi.org/10.1109/ukrcon.2017.8100505 